\title{
Body Fat Percentage, Waist Circumference and Body Mass Index are Correlated with Nitric Oxide Levels in Young Adults with Central Obesity
}

\author{
Feriyandi Nauli ${ }^{1}$, Nurhasanah² ${ }^{2}$ Endang Mahati ${ }^{3}$, Udin Bahrudin $^{4}$ \\ ${ }^{1}$ Postgraduate Program in Biomedical Sciences, Faculty of Medicine, Universitas Diponegoro, Semarang, Indonesia \\ ${ }^{2}$ Department of Nutrition Science, Faculty of Medicine, Universitas Riau, Pekanbaru, Indonesia \\ ${ }^{3}$ Department of Pharmacology and Therapy, Faculty of Medicine, Universitas Diponegoro, Semarang, Indonesia \\ ${ }^{4}$ Department of Cardiology and Vascular Medicine, Faculty of Medicine, Universitas Diponegoro, Semarang, Indonesia
}

Background: Central obesity stands for the corner-stone of cardio-metabolic health, while nitric oxide (NO) is a major regulator of cardiovascular function. To day, the correlation between serum NO metabolites nitrate/nitrite and the obesity components in young adults remains elusive. Thus, this current study was conducted to know the correlation between serum NO metabolites levels and body fat percentage, waist circumference (WC) as well as body mass index (BMI) in young adults with central obesity.

Materials and Methods: A cross-sectional study was conducted in Riau, Indonesia, involving 79 young adults aged 18-25 years, composing of 39 and 40 subjects with and without central obesity, respectively. Anthropometric measurements were performed to assess WC and BMI. Body fat percentage was measured using bioelectrical impedance analysis and serum NO metabolites levels were assessed using Griess methods.

Results: Levels of serum NO metabolites were significant higher in the subjects with central obesity $(168.41 \pm 12.64 \mu \mathrm{mol} / \mathrm{L})$ than that of normal subjects $(70.57 \pm 44.99 \mu \mathrm{mol} / \mathrm{L}, p<0.001)$, but the levels were no significant different between male and female subjects. Serum NO metabolites levels were strongly correlated with total body fat $(r=0.618, p<0.001)$, visceral fat $(r=0.733, p<0.001)$, subcutaneous fat $(r=0.547, p<0.001)$, WC $(r=0.717, p<0.001)$ and $\mathrm{BMI}(\mathrm{r}=0.788, p<0.001)$.

Conclusions: For young adults in Riau, Indonesia, levels of serum NO metabolites are higher in the central obesity group than that of the normal. In this population, body fat percentage, waist circumference and body mass index are correlated with serum nitric oxide metabolites levels.

Keywords: nitric oxide, body fat percentage, young adults, central obesity

Date of submission: May 11, 2020

Last Revised: June 12, 2020

Accepted for publication: June 19, 2020

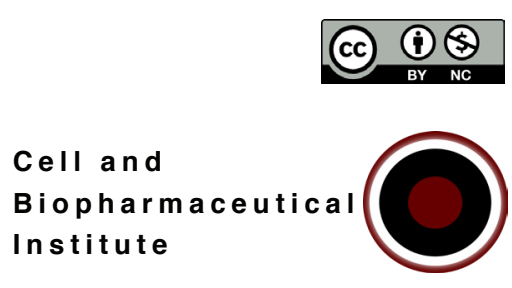

Corresponding Author:

Udin Bahrudin

Department of Cardiology and Vascular Medicine

Faculty of Medicine, Universitas Diponegoro

JI. Dr. Sutomo No. 16, Semarang 50231, Indonesia

E-mail: bahrudin00@gmail.com

Cell and
Biopharmaceutical
Institute

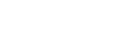




\section{Introduction}

Obesity is a build-up of abnormal or excessive adipose tissue which can interfere with the cardio-metabolic health of individuals. ${ }^{1}$ A simple parameter commonly used to classify obesity is body mass index (BMI). ${ }^{2}$ According to the World Health Organization (WHO) classification for Asia Pacific criteria, a person with a BMI of $\geq 23 \mathrm{~kg} / \mathrm{m}^{2}$ or $\geq 25 \mathrm{~kg} / \mathrm{m}^{2}$ is defined as overweight or obese, respectively. ${ }^{1-3}$ Subcutaneous adipose tissue (SAT) and visceral adipose tissue (VAT) are two main compartments of adipose tissue with different metabolic characteristics. ${ }^{4}$ Central obesity is characterized by escalated VAT around intra-abdominal organs. ${ }^{4}$ This obesity is associated with various pathological disorders consisting of impaired lipid and glucose metabolisms, insulin resistance and increased tendency for colon, breast and prostate cancers. ${ }^{4}$

Accurate measurements of body fat composition can carried out with sophisticated methods including magnetic resonance imaging (MRI), dual-energy X-ray absorptiometry (DXA) and computed tomography (CT) ${ }^{4,5}$ CT-Scan is the gold standard for measuring quantitative tissue of intra-abdominal fat. ${ }^{6}$ These methods in routine clinical practice cannot be applied since they are expensive, time-wasting, limited portability, requiring skilled staff, limited accessibility and radiation. Bioelectrical impedance analysis (BIA) is an alternative method for measuring body fat because it is fast, safe and non-invasive. ${ }^{4,5,7,8}$ BIA showed a significant strong correlation with $\mathrm{CT}$ in measuring of VAT and SAT ( $r=0.89$ and $r=0.85$, respectively) ${ }^{6}$ and also with MRI in determining body fat and VAT $(r=0.89$ and $r=$ 0.84 , respectively). ${ }^{9}$

Nitric oxide (NO) is a signaling and free radical molecule. It is synthetized from L-arginine by nitric oxide synthetase (NOS) in many cells in our body. ${ }^{10,11}$ In normal conditions, it is synthesized by endothelial-NOS (eNOS) and neuronal-NOS (nNOS) that played an important regulator of cardiovascular and renal function. ${ }^{12}$ Correlation between serum nitric oxide metabolites, i.e., nitrate and nitrite, and the obesity components remain elusive. Several studies showed there were positive correlation between $\mathrm{NO}$ metabolites and $\mathrm{BMI}^{13}$, between $\mathrm{NO}$ metabolites and body fat ${ }^{14}$, between NO metabolites and visceral fat ${ }^{15}$, while others studies showed negative correlation between NO metabolites and obesity ${ }^{16}$, between NO metabolites and abdominal adiposity. ${ }^{17} \mathrm{~A}$ few studies in Indonesia showed no statistical significant in those parameters. A study at
Padang showed that NO metabolites levels were higher in obese subjects than in the normal, but there were no significant correlation between NO metabolites and BMI. ${ }^{18}$ Another study in Yogyakarta found that NO metabolites were higher in male, aged more than 25 years and obese subjects than that of the control, but there were no statistical significant differences. ${ }^{19}$ Most population in the Padang study was adult, while in the Yogyakarta was young nonobese.

Thus, this study was conducted in young adults with central obesity in Riau, Indonesia, to know the correlation between serum nitric oxide levels and body fat percentage, waist circumference as well as body mass index.

\section{Materials and methods}

\section{Subjects}

This cross-sectional study was conducted in Riau, Indonesia, from December 2019 to February 2020. Subjects of study were college students aged 18-25 years old and selected by consecutive sampling. The WHO criteria for Asia Pacific was used to determine central obesity, i.e., waist circumference (WC) $\geq 90 \mathrm{~cm}$ and $\geq 80 \mathrm{~cm}$ for men and women, respectively. Subjects who pregnant, taking drugs (either hormonal therapy, steroid or aspirin), suffer from ascites, abdominal tumors, cardiovascular disease, kidney disease, diabetes mellitus, allergic diseases or diarrhea were excluded. Informed consent for participating in this study was obtained. The investigation conformed to the principles outlined in the Declaration of Helsinki ${ }^{20}$ and was approved by the institutional ethics committee of human research in Universitas Riau, number: B/227/UN.19.5.1.1.8/ UEPKK/2019.

\section{Anthropometric Measurements}

Anthropometric measurements were carried out to assess waist circumference $(\mathrm{cm})$, height $(\mathrm{cm})$ and weight $(\mathrm{kg})$ in a standing position. WC was measured at the midpoint between the edge of the last rib and the iliac crest without pressing the skin at the end of normal expiration using the met line. Weight and height were measured according to standard protocols. BMI was obtained from the calculation of body weight $(\mathrm{kg})$ divided by the square of height $\left(\mathrm{m}^{2}\right)$. Examination of body fat compositions was carried out using a BIA (Karada Scan HBF-375, Omron, Osaka, Japan) to measure the percentage of total body fat, visceral fat and subcutaneous fat. 


\section{NO Level Measurement}

Measurement of NO is difficult technically since its rapid oxidation in vivo, therefore, we measured its stable metabolites, nitrate/nitrite, as indirect measurement of levels of NO production. ${ }^{13,15,21}$ Venous blood samples were taken in the morning after fasting for 12 hours. Serum NO metabolites levels were measured using the Griess methods by employing QuantiChrom ${ }^{\mathrm{TM}}$ Nitric Oxide Assay Kit (Catologue no. D2NO-100, BioAssay Systems, California, USA) at the GAKI Laboratory, Universitas Diponegoro, Semarang, Indonesia. Briefly, serum samples were deproteinated by mixing $150 \mu \mathrm{L}$ serum with $8 \mu \mathrm{L}_{\mathrm{ZnSO}_{4}}$ and $8 \mu \mathrm{L} \mathrm{NaOH}$, then they were centrifuged for 10 minutes at $14,000 \mathrm{rpm}$. A total of $100 \mu \mathrm{L}$ of supernatant for each tube was transferred into another tube, and then $100 \mu \mathrm{L}$ Reagent A, $4 \mu \mathrm{L}$ Reagent B and $100 \mu \mathrm{L}$ Reagent $\mathrm{C}$ were added for the reduction of nitrate to nitrite and the measurement of nitrite in a single step. Those mixture were incubated for 10 minutes at $60^{\circ} \mathrm{C}$ prior transferring them into separated wells for detecting the signal density. The optical density was read at $540 \mathrm{~nm}$ using the enzyme-linked immunosorbent assay (ELISA) reader (ELx800, BioTek Instruments, Vermont, USA).

\section{Statistical Analysis}

Data analysis was performed using SPSS Software (SPSS Inc, Chicago, IL, USA; Version 25). Test normality with Kolmogorov-Smirnov for total subjects and Shapiro-Wilk for the central obesity and without central obesity subgroup. The comparison of sex and age proportions between groups was performed chi-square test, the comparison of total fat variables between groups using the IndependentT-test, while the comparison of visceral fat, subcutaneous fat, BMI, WC and NO metabolites levels between groups using Mann-Whitney-U test and also the comparison of NO metabolites levels between gender using Mann-Whitney-U. The correlation relationship between NO metabolites levels and percentage of body fat (total, visceral and subcutaneous fat), WC and BMI were measured using the Sperman's rho correlation test with $p<0.05$ significance value and $95 \%$ confidence interval. Differences with a $p$-value of $<0.05$ were considered statistically significant.

\section{Results}

A total 79 subjects were recruited, consisting of 39 and 40 subjects with and without central obesity, respectively. Among them, 44 (55.7\%) subjects were female. Table 1 shows the baseline clinical characteristics of the subjects with and without central obesity.

There were no significant differences $(p>0.05)$ in the proportion of gender and age variables between both groups. Significant differences were found for serum NO metabolites levels between subjects with central obesity $(168.41 \pm 12.64$ $\mu \mathrm{mol} / \mathrm{L})$ and without central obesity $(70.57 \pm 44.99 \mu \mathrm{mol} / \mathrm{L}$, $p<0.001)$. Total body fat, visceral fat, subcutaneous fat, WC and BMI were also significant differences between both groups.

Table 2 shows that there were no significant differences in the levels of serum NO metabolites between male and

Table 1. Subjects characteristics according to groups.

\begin{tabular}{|c|c|c|c|c|c|c|c|}
\hline \multirow[t]{2}{*}{ Variables } & \multicolumn{3}{|c|}{$\begin{array}{c}\text { Central Obesity Subjects } \\
(\mathrm{n}=39)\end{array}$} & \multicolumn{3}{|c|}{$\begin{array}{l}\text { Without Central Obesity Subjects } \\
\qquad(\mathrm{n}=40)\end{array}$} & \multirow[t]{2}{*}{$p$-value } \\
\hline & $\mathbf{n}$ & Mean \pm SD & (Min-Max) & $\mathbf{n}$ & Mean \pm SD & (Min-Max) & \\
\hline \multicolumn{8}{|l|}{ Gender } \\
\hline Male & 18 & & & 17 & & & $0.058^{\mathrm{a}}$ \\
\hline Female & 21 & & & 23 & & & \\
\hline Age (years) & & $18.7 \pm 0.9$ & $(18-21)$ & & $19.2 \pm 1.3$ & $(18-22)$ & $0.147^{\mathrm{b}}$ \\
\hline BMI $\left(\mathrm{kg} / \mathrm{m}^{2}\right)$ & & $30.55 \pm 4.54$ & $(23.8-43.3)$ & & $21.16 \pm 2.61$ & $(16.6-25.9)$ & $<0.001^{\mathrm{b}}$ \\
\hline Waist circumference $(\mathrm{cm})$ & & $96.50 \pm 11.17$ & $(80.5-129.5)$ & & $75.36 \pm 6.73$ & $(64.0-89.0)$ & $<0.001^{\mathrm{b}}$ \\
\hline Total body fat (\%) & & $33.23 \pm 5.08$ & $(21.0-42.1)$ & & $23.55 \pm 7.21$ & $(8.7-38.9)$ & $<0.001^{\mathrm{c}}$ \\
\hline Visceral fat (\%) & & $11.94 \pm 5.52$ & $(3.5-29.0)$ & & $3.68 \pm 2.25$ & $(0.5-8.5)$ & $<0.001^{\mathrm{b}}$ \\
\hline Subcutaneous fat (\%) & & $28.28 \pm 7.60$ & $(15.0-41.1)$ & & $18.66 \pm 6.70$ & $(6.4-30.3)$ & $<0.001^{\mathrm{b}}$ \\
\hline Serum nitric oxide metabolites levels $(\mu \mathrm{mol} / \mathrm{L})$ & & $168.41 \pm 12.64$ & $(138.6-200.1)$ & & $70.57 \pm 44.99$ & $(22.1-150.2)$ & $<0.001^{\mathrm{b}}$ \\
\hline
\end{tabular}

Note: ${ }^{\mathrm{a} C h i}$-square test, ${ }^{\mathrm{b}}$ Mann Whitney U test, ${ }^{\mathrm{C}}$ Independent $\mathrm{T}$ test. 
Table 2. Serum nitric oxide metabolites levels according to sex in the study subjects.

\begin{tabular}{|c|c|c|c|c|c|c|c|c|c|}
\hline \multirow{2}{*}{ Gender } & \multicolumn{3}{|c|}{ Central Obesity Subjects } & \multicolumn{3}{|c|}{ Without Central Obesity Subjects } & \multicolumn{3}{|c|}{ Total Subjects } \\
\hline & Mean \pm SD & (Min-Max) & p-value & Mean \pm SD & (Min-Max) & p-value & Mean \pm SD & (Min-Max) & p-value \\
\hline Male & $164.79 \pm 13.27$ & $138.6-184.7$ & \multirow{2}{*}{$0.135^{\mathrm{a}}$} & $77.31 \pm 48.78$ & $22.1-148.0$ & \multirow{2}{*}{$0.712^{\mathrm{a}}$} & $122.30 \pm 56.35$ & $22.1-184.7$ & \multirow{2}{*}{$0.875^{\mathrm{a}}$} \\
\hline Female & $171.50 \pm 11.48$ & $153.6-200.1$ & & $65.59 \pm 42.38$ & $23.0-150.2$ & & $116.14 \pm 62.00$ & $23.00-200.1$ & \\
\hline
\end{tabular}

Note: ${ }^{a}$ Mann Whitney U test.

female, in either all subjects, ones with or without central obesity, with respective $p$-value $0.875,0.135$ and 0.712 .

Table 3 shows that all variables had correlation with serum NO metabolites levels; they were total body fat percentage $(\mathrm{r}=0.618, p<0.001)$, visceral fat $(\mathrm{r}=0.733$, $p<0.001)$, subcutaneous fat $(\mathrm{r}=0.547, p<0.001)$, WC $(\mathrm{r}=0.717, p<0.001)$ and BMI $(\mathrm{r}=0.788, p<0.001)$.

\section{Discussion}

Correlation between serum NO metabolites and the obesity components in young adults with central obesity remains elusive. This study was conducted to know the correlation between body fat percentage and serum NO metabolites in those subjects and we found that levels of the serum NO metabolites were strongly correlated with body fat percentage, WC and BMI. To the best of our knowledge, this is the first data about this issue reported from particular population of Indonesian young adult subjects with obesity.

These results are in line with several previous studies that found higher levels of serum nitric oxide metabolites in obese subjects. Study of 313 children aged 8 to 9 years in Portugal concluded that the increase in serum NO metabolites levels was related to the total body fat ${ }^{12}$, as well as the study in Poland of 154 women grouped by BMI found positive correlation between the total body fat BMI with serum NO metabolites levels. ${ }^{22}$ Similar research results were also obtained in a South Korean study of 363 subjects aged 14 to 19 years which concluded that obesity causes an increase in NO production in humans, the increasing in serum NO metabolites levels is strongly correlated with obesity, total body fat and BMI. ${ }^{14}$ The study of 110 children aged 7 to 14 years in Spain found higher and significant serum NO metabolites levels in obese children compare to normal weight children. ${ }^{23}$ Contradictory research results were reported in a study of 114 adolescents (aged 14.01 \pm 3.19 ) in Austria, there was a decrease serum NO metabolites levels in obese adolescents, serum NO metabolites levels were negatively correlated with BMI. ${ }^{16}$ Japanese study of 486 subjects aged 40-84 years concluded that there was an inverse relationship between NO bioactivity and accumulation of abdominal fat measured using WC and waist-hip circumference ratio. ${ }^{17}$ Taken together, in obese young adults, the high levels of serum NO metabolites are correlated positively with central obesity; but in adolescents, the correlation are inversely.

The subject criteria as well as the result of this study were different from two previous studies conducted in Indonesia. ${ }^{18,19}$ A study in Padang involved 130 subjects,

Table 3. The correlation between serum NO metabolites levels and body fat percentage, WC, as well as BMI.

\begin{tabular}{|c|c|c|c|c|c|c|}
\hline \multirow{3}{*}{ Variables } & \multicolumn{6}{|c|}{ Serum NO Metabolites Levels } \\
\hline & \multicolumn{2}{|c|}{$\begin{array}{l}\text { Central Obesity } \\
\text { Subjects }\end{array}$} & \multicolumn{2}{|c|}{$\begin{array}{c}\text { Without Central Obesity } \\
\text { Subjects }\end{array}$} & \multicolumn{2}{|c|}{ Total Subjects } \\
\hline & $\mathbf{r}$ & p-value & $\mathbf{r}$ & $p$-value & $\mathbf{r}$ & p-value \\
\hline Total body fat & 0.370 & $0.020^{\mathrm{a}}$ & 0.064 & $0.695^{\mathrm{b}}$ & 0.618 & $<0.001^{\mathrm{b}}$ \\
\hline Visceral fat & 0.257 & $0.115^{\mathrm{b}}$ & 0.109 & $0.504^{b}$ & 0.733 & $<0.001^{\mathrm{b}}$ \\
\hline Subcutaneous fat & 0.383 & $0.016^{\mathrm{b}}$ & 0.023 & $0.886^{\mathrm{b}}$ & 0.547 & $<0.001^{\mathrm{b}}$ \\
\hline Waist circumference & 0.037 & $0.821^{\mathrm{b}}$ & 0.058 & $0.722^{\mathrm{b}}$ & 0.717 & $<0.001^{\mathrm{b}}$ \\
\hline Body mass index & 0.352 & $0.028^{b}$ & 0.105 & $0.520^{\mathrm{b}}$ & 0.788 & $<0.001^{\mathrm{b}}$ \\
\hline
\end{tabular}

Note: aPearson correlation test, 'Spearman's Rho correlation test. 
$92.3 \%$ of them were adult aged 40 to 65 years. ${ }^{18}$ Another study was conducted in Yogyakarta which recruited 44 subjects whom $81.8 \%$ were young aged 18 to 24 years, but $70.5 \%$ were non-obese. ${ }^{19}$ Both the studies found no significant differences in NO metabolites levels between obese and non-obese subjects. ${ }^{18,19}$ However, these studies did not mention the exclusion criteria and the preparation of subjects prior taking the blood samples. These are important since the levels of $\mathrm{NO}$ are affected by both diet and comorbid of the subjects.

The high levels of NO metabolites in obese subjects is caused by an increase of NO production in adipose tissue $^{22,24,25}$ as a compensatory mechanisms for changes related to obesity. ${ }^{13,23}$ The presence of endothelial NO synthase (eNOS) and inducible-NOS (iNOS) in the adipose cells induces the NO production. ${ }^{15,26,27}$ Each of them produces NO with different rates. ${ }^{26}$ The eNOS generates a smaller amount of NO compared to iNOS which has the biggest capacity to produce NO. ${ }^{21,26}$ Under physiological conditions, eNOS is a dominant isoform in the adipose tissue compared to iNOS..$^{21,25}$ In obesity, accumulation of proinflammatory macrophages in adipose tissue is responsible for most of iNOS expressions by promoting its expression. ${ }^{26}$ In patients with obesity, the hypertrophic adipocytes reduce a diffusion ability of oxygen and the reduction in vascularization promotes hypoxia. ${ }^{27}$ Under the hypoxic conditions, endogenous NO production increase due to the increased iNOS expression rather than the eNOS. ${ }^{21,26,27}$ Thus, iNOS produces large amounts of NO as a defensive mechanism. ${ }^{28}$

In the population-based studies, the origin of NO metabolites values in young obese subjects cannot be distinguished whether they are from eNOS or iNOS, since the difficulty in measuring of NO levels in vivo. ${ }^{21,29} \mathrm{NO}$ is a gaseous and has a very short half-life, ranging from 0.05 milliseconds to 30 seconds, depending on the environment and reactant availability. ${ }^{26-29}$ Inability to distinguish the eNOS and iNOS components in serum NO metabolites is a limitation of this study as well as other population-base studies. The existence of inflammation in the subject of this study could not be confirmed since we did not check any marker of inflammation.

$\mathrm{NO}$ production is divided into two independent pathways, i.e., $\mathrm{NOS}$ pathway and the $\mathrm{NO}_{3}^{-}-\mathrm{NO}_{2}^{-}-\mathrm{NO}$ pathway. ${ }^{21}$ These pathways make the meaning of a high serum NO metabolites levels more intricate, unless a well- controlled food intake of nitrates and nitrites. ${ }^{21}$ Nitrates do not have first-pass metabolism, so after consumption of food, their level increases rapidly within 15 minutes, peaking at 90 minutes with a half-life of $\mathrm{NO}_{3}^{-} 5$ to 8 hours. ${ }^{21,27}$ Under normal conditions, both sources of NO contribute equally to the overall formation of NO. ${ }^{30}$ During fasting condition, serum NO metabolites level is weakly correlated with $\mathrm{NO}_{3}{ }^{-}$consumption in a regular diet. ${ }^{21}$ Under physiological conditions, fasting plasma $\mathrm{NO}_{2}{ }^{-}$reflects up to $80 \%$ of endogenous NO production..$^{21}$ The current study did not control the diet of the subjects prior to the blood sample collection except a fasting for overnight.

The association between high intake of L-arginine and NO synthesis remains unclear. An increase NO metabolites level was observed after oral supplementation of $6 \mathrm{~g}$ /day L-arginine for 2 months in diabetic patients with atherosclerotic peripheral arterial disease. ${ }^{31} \mathrm{~A}$ high dietary intake of L-arginine was also strongly associated with serum NO metabolites levels in overweight and obese subjects, but not in subjects with normal weight. ${ }^{32}$ An acute oral supplementation of $6 \mathrm{~g} \mathrm{~L}$-arginine in healthy subjects did not showed a significant change of NO metabolites level compared to the placebo group. ${ }^{33,34}$ The mechanism how the supplementation of L-arginine increased endogenous NO production is not fully understood. This is due to normal L-arginine level greatly exceeds the Michaelis constant $(\mathrm{Km})$ of eNOS, therefore, increase of L-arginine concentration will not change the production of eNOS. ${ }^{35}$ The current study did not calculate L-arginine dietary intake of the subjects prior blood sample collection.

Obesity with high NO metabolites levels may cause more deleterious effects. ${ }^{12}$ The increased expression and function of iNOS causes the excessive NO production and the disturbed eNOS affects the decreased NO bioavailability. Both of them promote the growth of non-communicable diseases such as type 2 diabetes mellitus, hypertension, coronary heart disease, kidney disorders and various types of cancer. ${ }^{21}$ Data of the current study that levels of serum NO metabolites were higher in obese subjects than that of the normal control indicated an alarm on the future disease for those subjects.

This study also found that there were no significant differences in serum NO metabolites levels between men and women. These results are similar to data of other studies. ${ }^{16,17}$ Although another study found inversely result. ${ }^{19,36}$ This warrant for future study. 


\section{Conclusion}

For young adults in Riau, Indonesia, the levels of serum NO metabolites are higher in the central obesity group than that of the normal. In this population, the body fat percentage, waist circumference and body mass index are correlated with serum nitric oxide metabolites levels.

\section{References}

1. WHO/IASO/IOTF. The Asia-Pacific Perspective : Redefining Obesity and its treatment. Sydney: WHO; 2000.

2. WHO [Internet]. Obesity and overweight [updated 2018 Apr 1; cited $2019 \mathrm{Jul} 21$ ]. Available from: https://www.who.int/news-room/factsheets/detail/obesity-and-overweight.

3. Lim JU, Lee JH, Kim JS, Hwang Y Il, Kim TH, Lim SY, et al. Comparison of World Health Organization and Asia-Pacific body mass index classifications in COPD patients. Int J COPD. 2017; 12 : 2465-75.

4. Shuster A, Patlas M, Pinthus JH, Mourtzakis M. The clinical importance of visceral adiposity: A critical review of methods for visceral adipose tissue analysis. Br J Radiol. 2012; 85(1009): 1-10.

5. Ramírez-Vélez R, Correa-Bautista JE, Martínez-Torres J, González-Ruíz K, González-Jiménez E, Schmidt-RioValle J, et al. Performance of two bioelectrical impedance analyses in the diagnosis of overweight and obesity in children and adolescents: The FUPRECOL Study. Nutrients. 2016; 8(10): 1-13.

6. Park KS, Lee DH, Lee J, Kim YJ, Jung KY, Kim KM, et al. Comparison between two methods of bioelectrical impedance analyses for accuracy in measuring abdominal visceral fat area. $\mathrm{J}$ Diabetes Complications. 2016; 30(2): 343-9.

7. Lu HK, Chen YY, Yeh C, Chuang CL, Chiang LM, Lai CL, et al. Discrepancies between leg-to-leg bioelectrical Impedance analysis and computerized tomography in abdominal visceral fat measurement. Sci Rep. 2017; 7(1): 1-8.

8. Day K, Kwok A, Evans A, Mata F, Verdejo-Garcia A, Hart K, et al. Comparison of a bioelectrical impedance device against the reference method dual energy X-ray absorptiometry and anthropometry for the evaluation of body composition in adults. Nutrients. 2018; 10(10): 1469. doi: 10.3390/nu10101469.

9. Wang JG, Zhang Y, Chen HE, Li Y, Cheng XG, Xu L, et al. Comparison of two bioelectrical impedance analysis devices with dual energy $x$-ray absorptiometry and magnetic resonance imaging in the estimation of body composition. J Strength Cond Res. 2013; 27(1): 236-43.

10. Uppalapati A, Gogineni S, Espiritu JR. Association between body mass index (BMI) and fraction of exhaled nitric oxide (FeNO) levels in the National Health and Nutrition Examination Survey (NHANES) 2007-2010. Obes Res Clin Pract. 2016; 10(6): 652-8.

11. Ahmad A, Dempsey S, Daneva Z, Azam M, Li N, Li PL, et al. Role of nitric oxide in the cardiovascular and renal systems. Int J Mol Sci. 2018; 19(9): 2605. doi: 10.3390/ijms19092605.

12. Correia-Costa L, Sousa T, Morato M, Cosme D, Afonso J, Areias $\mathrm{JC}$, et al. Oxidative stress and nitric oxide are increased in obese children and correlate with cardiometabolic risk and renal function. Br J Nutr. 2016; 116(5): 805-15.

13. Ghasemi A, Zahediasl S, Azizi F. Elevated nitric oxide metabolites are associated with obesity in women. Arch Iran Med. 2013; 16(9): 521-5.

14. Choi JW, Pai SH, Kim SK, Ito M, Park CS, Cha YN. Increases in nitric oxide concentrations correlate strongly with body fat in obese humans. Clin Chem. 2001; 47(6): 1106-9.

15. Fujita K, Wada K, Nozaki Y, Yoneda M, Endo H, Takahashi H, et al. Serum nitric oxide metabolite as a biomarker of visceral fat accumulation: Clinical significance of measurement for nitrate/ nitrite. Med Sci Monit. 2011; 17(3): CR123-31.

16. Gruber HJ, Mayer C, Mangge H, Fauler G, Grandits N, WildersTruschnig M. Obesity reduces the bioavailability of nitric oxide in juveniles. Int J Obes. 2008; 32(5): 826-31.

17. Kondo T, Ueyama J, Imai R, Suzuki K, Ito Y. Association of abdominal circumference with serum nitric oxide concentration in healthy population. Environ Health Prev Med. 2006; 11(6): 321-5.

18. Purwadianti N, Oenzil F, Sulastri D. Hubungan antara indeks massa tubuh dengan kadar nitrit oksid pada masyarakat etnik Minangkabau di Kota Padang. J Kesehat Andalas. 2015; 4(2): 364-8.

19. Susilowati A, Akrom, Darmawan E. Profile of nitric oxide (NO) levels in Yogyakarta society. J Health Med Nursing. 2015: 17(2015): 38-42.

20. World Medical Association. World Medical Association Declaration of Helsinki: ethical principles for medical research involving human subjects. JAMA. 2013; 310(20): 2191-4.

21. Bahadoran Z, Mirmiran P, Jeddi S, Carlström M, Azizi F, Ghasemi A. Circulating markers of nitric oxide homeostasis and cardiometabolic diseases: insights from population-based studies. Free Radic Res. 2019; 53(4): 359-76.

22. Olszanecka-Glinianowicz M, Zahorska-Markiewicz B, Janowska J, Zurakowski A. Serum concentrations of nitric oxide, tumor necrosis factor (TNF)- $\alpha$ and TNF soluble receptors in women with overweight and obesity. Metabolism. 2004; 53(10): 1268-73.

23. Codoñer-Franch P, Tavárez-Alonso S, Murria-Estal R, Megías-Vericat J, Tortajada-Girbés M, Alonso-Iglesias E. Nitric oxide production is increased in severely obese children and related to markers of oxidative stress and inflammation. Atherosclerosis. 2011; 215(2): 475-80.

24. Foroumandi E, Alizadeh M, Kheirouri S, Asghari Jafarabadi M. Exploring the role of body mass index in relationship of serum nitric oxide and advanced glycation end products in apparently healthy subjects. PLoS One. 2019; 14(3): e0213307. doi: 10.1371/journal. pone. 0213307 .

25. Engeli S, Janke J, Gorzelniak K, Böhnke J, Ghose N, Lindschau C, et al. Regulation of the nitric oxide system in human adipose tissue. $\mathrm{J}$ Lipid Res. 2004; 45(9): 1640-8.

26. Sansbury BE, Hill BG. Regulation of obesity and insulin resistance by nitric oxide. Free Radic Biol Med. 2014; 73: 383-99.

27. Ghasemi A, Jeddi S. Anti-obesity and anti-diabetic effects of nitrate and nitrite. Nitric Oxide. 2017; 70(24): 9-24.

28. Khazan M, Hdayati M. The role of nitric oxide in health and diseases. Scimetr. 2014; 3(1): 1-10.

29. Caimi G, Hopps E, Montana M, Carollo C, Calandrino V, Incalcaterra $\mathrm{E}$, et al. Nitric oxide metabolites (nitrite and nitrate) in several clinical condition. Clin Hemorheol Microcirc. 2014; 56(4): 359-69.

30. Carlström M, Liu M, Yang T, Zollbrecht C, Huang L, Peleli M, et al. Cross-talk between nitrate-nitrite-NO and NO synthase pathways in control of vascular NO homeostasis. Antioxid Redox Signal. 2015; 23(4): 295-306. 
31. Jabłecka A, Bogdański P, Balcer N, Cieślewicz A, Skołuda A, Musialik $\mathrm{K}$. The effect of oral L-arginine supplementation on fasting glucose, $\mathrm{HbA1c}$, nitric oxide and total antioxidant status in diabetic patients with atherosclerotic peripheral arterial disease of lower extremities. Eur Rev Med Pharmacol Sci. 2012; 16(3): 342-50.

32. Mirmiran P, Bahadoran Z, Ghasemi A, Azizi F. The association of dietary L-arginine intake and serum nitric oxide metabolites in adults: a population-based study. Nutrients. 2016; 8(5): 331. doi: 10.3390/nu8050311.

33. Alvares TS, Conte-Junior CA, Silva JT, Paschoalin VMF. Acute L-arginine supplementation does not increase nitric oxide production in healthy subjects. Nutr Metab (Lond). 2012; 9(1): 54. doi: 10.1186/1743-7075-9-54.

34. Meirelles CM, Matsuura C. Acute supplementation of L-arginine affects neither strength performance nor nitric oxide production. J Sports Med Phys Fitness. 2018; 58(3): 216-20.

35. Khalaf D, Krüger M, Wehland M, Infanger M, Grimm D. The effects of oral L-arginine and L-citrulline supplementation on blood pressure. Nutrients. 2019;11(7): 1679. doi: 10.3390/nu11071679.

36. Ghasemi A, Zahedi Asl S, Mehrabi Y, Saadat N, Azizi F. Serum nitric oxide metabolite levels in a general healthy population: relation to sex and age. Life Sci. 2008; 83(9-10): 326-31. 